\title{
DNA Gene Expression to Study Immunologic Mechanisms for the Long-Term Cure of Malaria in Babies and Children in South-Western Nigeria
}

\author{
Jerry T. Thornthwaite1, Akanni E. Olufemi², Ayankunle A. Ademola ${ }^{3}$, 0. A. T. Alli² \\ ${ }^{1}$ Cancer Research Institute of West Tennessee, Henderson, USA \\ ${ }^{2}$ Medical Laboratory Science Department, College of Health Sciences, Ladoke Akintola University of Technology, Osogbo, Osun \\ State, Nigeria \\ ${ }^{3}$ Pharmacology \& Therapeutics Department, College of Health Sciences, Ladoke Akintola University of Technology, Osogbo, \\ Osun State, Nigeria \\ Email: jtt@criwt.com
}

How to cite this paper: Thornthwaite, J.T., Olufemi, A.E., Ademola, A.A. and Alli, O.A.T. (2019) DNA Gene Expression to Study Immunologic Mechanisms for the Long-Term Cure of Malaria in Babies and Children in South-Western Nigeria. Advances in Biological Chemistry, 9, 68-87. https://doi.org/10.4236/abc.2019.92006

Received: March 1, 2019

Accepted: April 23, 2019

Published: April 26, 2019

Copyright (๑) 2019 by author(s) and Scientific Research Publishing Inc. This work is licensed under the Creative Commons Attribution International License (CC BY 4.0).

http://creativecommons.org/licenses/by/4.0/

\begin{abstract}
Malaria infection has been a very serious public health problem in Nigeria and most parts of Africa. Development of antimalarial treatments capable of providing a permanent cure for malaria has been a herculean task for drug researchers. A trial of a novel, proprietary blend formulation (Triantimal ${ }^{\mathrm{TM}}$ ) in gel caps for children $(\mathrm{n}=112)$ and water-soluble, $18.51 \mathrm{~nm}$ diameter, $\mathrm{Nu}$ traNanoSphere ${ }^{\mathrm{TM}}$ encapsulated Triantimal ${ }^{\mathrm{TM}}$ drops for babies (19.9 Months \pm 8.7 SD, $\mathrm{n}=15$ ) was conducted in Osogbo, Nigeria. The enrolled subjects were screened for malaria, treated with Triantimal ${ }^{\mathrm{TM}}$ for 16 consecutive days and sera collected on days $0,5,10,16,30,60$, and 730 . Also, 31 of the children donated buffy coat samples for the gene expression studies when sera were collected. The children showed $90.2 \%$ parasite-free at 60 days and $85.1 \%$ at 730 days. The babies revealed $93.3 \%$ parasite-free at 60 days. These data show for the first time a real possibility for a cure of malaria in Nigeria. The one-time, low dose, extended treatment and synergism of the natural components minimize the ability of the parasites to develop resistance, while boosting the immune system. Indeed, the DNA amplification data showed that all aspects of the humoral, innate, and innate defensin immunity are involved in the long-term immunity against $P$. falciparum in which may be termed a type of "in vivo immunization".
\end{abstract}

\section{Keywords}

Triantimal $^{\mathrm{TM}}$, NutraNanoSpheres ${ }^{\mathrm{TM}}$, Immunity, qPCR, Gene Expression, 


\section{Introduction}

Half of the world's population, over 3.3 billion people are at risk of malaria of which 1.2 billion are at high risk and 97 countries have ongoing malaria transmission. Nowhere is this challenge greater than Africa and specifically in Nigeria. Nigeria has more reported cases of malaria and deaths due to malaria than any other country in the world, where there are estimated 100 million malaria cases with over 300,000 deaths per year due to the most serious type of malaria, Plasmodium falciparum [1]. The virulence of $P$. falciparum is closely associated with its immune response-evading ability, which is more complicated by the involvement of blood-brain barrier disruption followed by leukocyte infiltration [1].

Individuals living in malaria endemic areas may become clinically immune after multiple re-infections over time and remain infected without apparent symptoms. However, why a long time period is required to gain clinical immunity to malaria is not clear [1].

Many diseases, including malaria, tuberculosis, and acquired immune deficiency syndrome (AIDS) have not been good vaccine candidates, and intrinsic barriers may impede approaches limited solely to generating antibodies. In 2017, the result of final clinical trial of the first viable malaria vaccine offers only partial protection against malaria for up to four years. The vaccine is called RTS, S and has been developed over the past 30 years by GlaxoSmithKline Pharmaceuticals and the Bill \& Melinda Gates Foundation at an estimated cost exceeding over a half a billion dollars. The RTS, S is designed for children in African countries and is approved by international regulators. However, early trial data from 2011 and 2012-carried out on 16,000 children from seven African countries-showed that vaccines in babies aged 5 - 17 months were only effective in $46 \%$ of the cases, diminishing hopes that RTS, $S$ will be a viable vaccine [2].

In this paper, we present a type of "in vivo vaccination" in children and babies that may complement the current vaccine studies with malaria. This research presents the role humoral, cellular, and innate immunity play in our high cure rates with long-term protection against malaria re-infection. Our malaria formulation does not require refrigeration, booster reapplication, and is a one-time treatment regiment for 16 days, which results in long-term immunity over 14 years (Haiti examples) or two years so far in Nigeria.

The objectives of this study include assessment of the antimalarial efficacy of a micellized, water-soluble liquid version for babies and gel caps for children of TriAntiMal $^{\mathrm{TM}}$ and are to report the analyses of buffy coat samples during and after treatment for DNA gene expression to determine why patients experience long-term immunity.

\section{Materials and Methods}

Study site: The study was conducted at the Primary Health Centre, Sabo area, 
Olorunda local Government, European-Union Prime project facility, Osogbo, Osun State. Nigeria. The study was approved by the UNIOSUN Health Research Committee with monitoring by designated representatives of the HREC committee. One hundred children, ages between 2 and 15 years old, were recruited into the study to determine the overall curative rate of Plasmodium falciparum in the patients. Babies, 9 - 36 months old with active malaria, were treated with the water-soluble formulation.

Study design: Patients were screened for fever by using infra red thermometer and those found to have temperatures $37.5^{\circ} \mathrm{C}-38.4^{\circ} \mathrm{C}$. The axillary temperature of selected patients was further checked to fall within the values stated above before they were referred for a Giemsa-stained thick blood smear. Those with a positive smear results were assessed by study clinicians for the following inclusion criteria: Patient diagnosed to have malaria with parasitemia load of 2,000 - 100,000 parasites/ $\mu$; fever with axillary temperature greater or equal to $37.5^{\circ} \mathrm{C}$; age 2 - 15 years; HIV screened negative; those who would be available to have their blood drawn as scheduled; willingness to comply with the daily oral medicine of 16 days.

Patient Exclusion criteria included the following: unwillingness to take the Malaria Formulation for 16 consecutive days; concomitant infection, i.e., malaria infected patient that has any other infection; treatment with any anti-malaria in the next one week before presentation; acute severe complicated malaria e.g. vomiting frequently that requires the administration of intravenous fluid, convulsion, severe anaemia with $\mathrm{PCV}<18 \%$, clinical evidence of pulmonary oedema, feature suggestive of renal failure, history of dark brown color urine which is suggestive of severe red blood cell haemolysis; hyperparasitemia with $>10^{5}$ parasites $/ \mu \mathrm{l}$; Patient with temperature $>37.5^{\circ} \mathrm{C}$; hyperpyrexia with temperature $\geq$ $40^{\circ} \mathrm{C}$; low density Parasitemia: $<2 \times 10^{3}$ parasite per micro litre; HIV screened positive; and inability to obtain parental consent.

All treatments were directly administered at the clinic and patients observed for 30 minutes and doses re-administered when vomiting occurred, but those with repeated vomiting on day 0 were excluded from the study.

Laboratory procedures. Blood smears were air dried, stained with a $2 \%$ Giemsa solution for $15 \mathrm{~min}$, rinsed with water and re-air dried and viewed under the microscope using oil immersion lens. Parasite densities were calculated from thick smears as the number of asexual parasites per 200 leukocytes (or per 500 leukocytes if the parasite density was $<10$ parasites per 200 leukocytes), assuming a leukocyte count of $6 \times 10^{3}$ leukocytes/ $\mu \mathrm{L}$. Smear findings were considered negative when microscopic examination of 100 high-power fields did not reveal parasites. Counts were performed by two microscopists and discrepant readings resolved by a third reader. Thin blood smears were performed to evaluate parasite species. Packed cell volume was measured from finger-prick blood samples using heparinised capillary tube. HIV screening tests were done by finger prick sampling using accurate and Determine HIV strips, respectively. Five ml of venous blood were taken, and the buffy coats sera were sent to USA for further investigations by Dr. Thornthwaite at the Institute for immunological and DNA gene 
amplification analyses.

\section{Sample collection schedule:}

HIV screening on day 0; thick blood film for malaria parasite on days $0,1,2,3$, $7,14,30$, and 60 ; thin blood film for malaria parasite and haematocrit on days 0,7 , 14, 30 and 60; and sera for immunologic testing on days $0,5,10,16,30$ and 60.

To understand the immune processes involved in long-term immunity, serums $(\mathrm{n}=112)$ and buffy coats $(\mathrm{n}=31)$ were from the original children at days $0,5,10,16,30,60$, and 730 . In this paper, data will also be presented with new children $(\mathrm{n}=51)$ and adults $(21)$. Babies, using a new water soluble proprietary NutraNanoSphere $^{\mathrm{TM}}$ (NNS) encapsulation method, were treated over a 16-day period with the water-soluble NNS TriAntiMal ${ }^{\mathrm{TM}}$ and serum and buffy coat samples were obtained at $0,16,30$, and 60 days.

Drug provision: The TriAntiMal ${ }^{\mathrm{TM}}$ formulations were supplied by Dr Jerry $\mathrm{T}$. Thornthwaite, Director of the Cancer Research Institute of West Tennessee. Each gel capsule TriAntiMal ${ }^{\mathrm{TM}}$ contains a proprietary blend of $50 \mathrm{mg}$ antioxidant citrus bioflavonoids including synephrine, artemisinin, quercetin, curcuminoids, hesperetin, plus flavonoids and $50 \mathrm{mg}$ artemisinin (97\%) (patent pending). The NNS TriAntiMal ${ }^{\mathrm{TM}}$ contained a proprietary blend of micellized artemisinin, bilberry and curcumin.

The NNS TriAntiMal ${ }^{\mathrm{TM}}$ Formulation was encapsulated in micelles of a natural origin with an average sphere diameter of $18.51 \mathrm{~nm} \pm 7.45 \mathrm{SD}$. These formulation contained mixtures of micellized curcumin, bilberry and artemisinin. This Formulation is completely miscible in the baby's milk and virtually has no taste. These NNS do not require refrigeration, naturally are antibacterial, and are very stable, even at elevated temperatures $\left(37^{\circ} \mathrm{C}\right)$ for several days.

Average Diameter Measurements of the NNS: The samples were diluted by volume in a ratio of 1:6 with DI Water and filtered by a $0.45 \mu \mathrm{m}$ Nylon membrane to remove any dust contaminants. The Zetasizer ZSP (Malvern Instruments) was used with a backscattering angle of 173 degrees to measure the particle size by dynamic light scattering. A non-negative least squares algorithm was used to generate the size distribution by intensity, which indicated the diameter of the major population for the Malaria NNS. The intensity data was then converted to a mass or volume distribution to compare relative amounts of each size

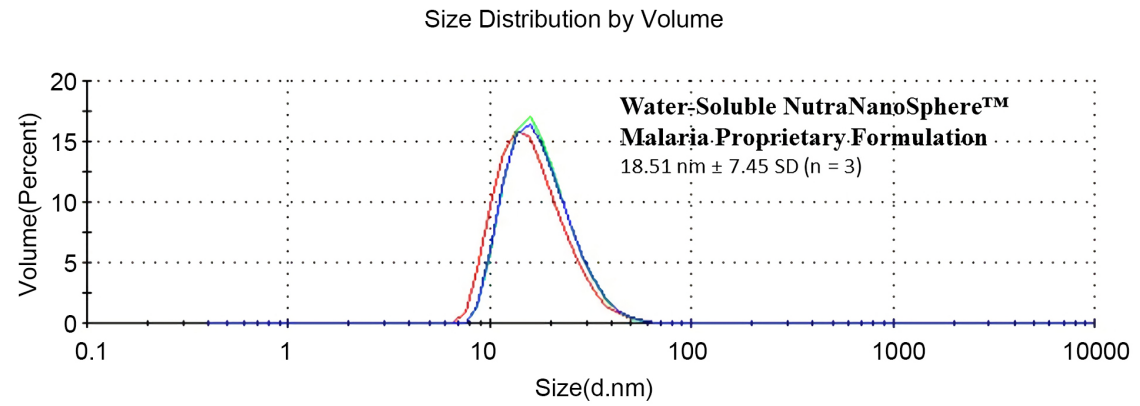

Figure 1. Water Soluble NutraNanoSphere ${ }^{\mathrm{TM}}$ Triantimal $^{\mathrm{TM}}$ Malaria Proprietary Formulation for Babies. 
population which indicated the percentage of the sample represent in the respective population as shown in Figure 1.

Drug administration: Using the TriAntiMal ${ }^{\mathrm{TM}}$ treatment designated for this study was the Malaria medicine designate.

Handling of adverse effects: Symptoms and signs that were not part of presenting features were taking as adverse effects. Though bilberry, other bioflavonoids, artemisinin and curcumin are known to be safe, adequate medical personnel were available to take care of any side effects. There were no noticeable adverse side effects of the drug observed during or post treatment.

Confidentiality: Data were handled by the researchers and the names of each patient coded.

Alternative treatment: Dihydroartemisinin/piperaquine fixed antimalarial combination was administered to patients who withdrew from the study before parasitemia was cleared or patients that fail on the study drug.

Ethical clearance: This was obtained from Ethical Committee, Osun State University, Osogbo, Nigeria.

Data analysis: All data were analyzed statistically using standard deviations and the analysis of True Population Proportion Curve Rate at 95\% confidence limits and $\mathrm{p}$ values determined. Standard deviations for $13-16$ patient groups were determined and the results of these are shown in Tables 1-6 and Figure 2 and Figure 3.

Buffy Coat Samples: Buffy Coat blood was obtained from 31 children as approved by the human ethics committee study with our investigator/researcher as described previously. Part of the study used 16 buffy coat patients chosen randomly for the complementary DNA (cDNA) preparation. The blood was obtained from children being treated with the TriAntiMal ${ }^{\mathrm{TM}} 16$-day protocol. Before,

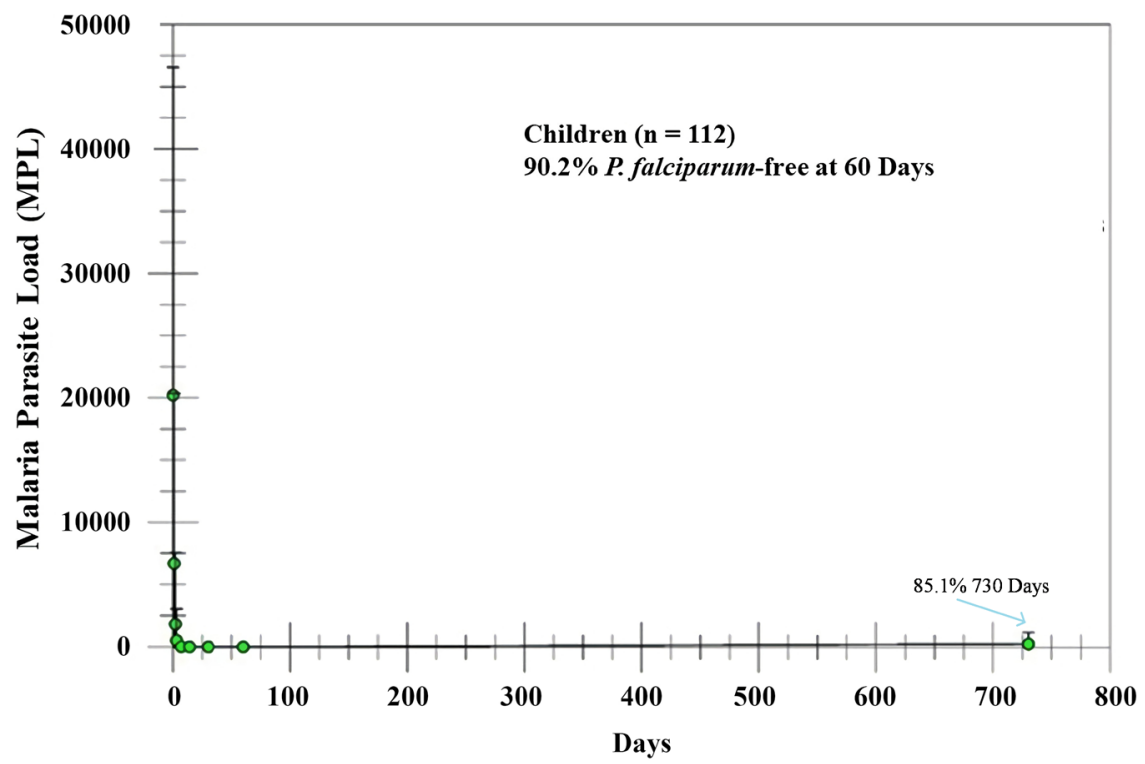

Figure 2. Malaria Parasite Clearance during and after treatment for 730 days. A 5.1\% parasite recurrence was experienced at two years. SD bars are shown. 


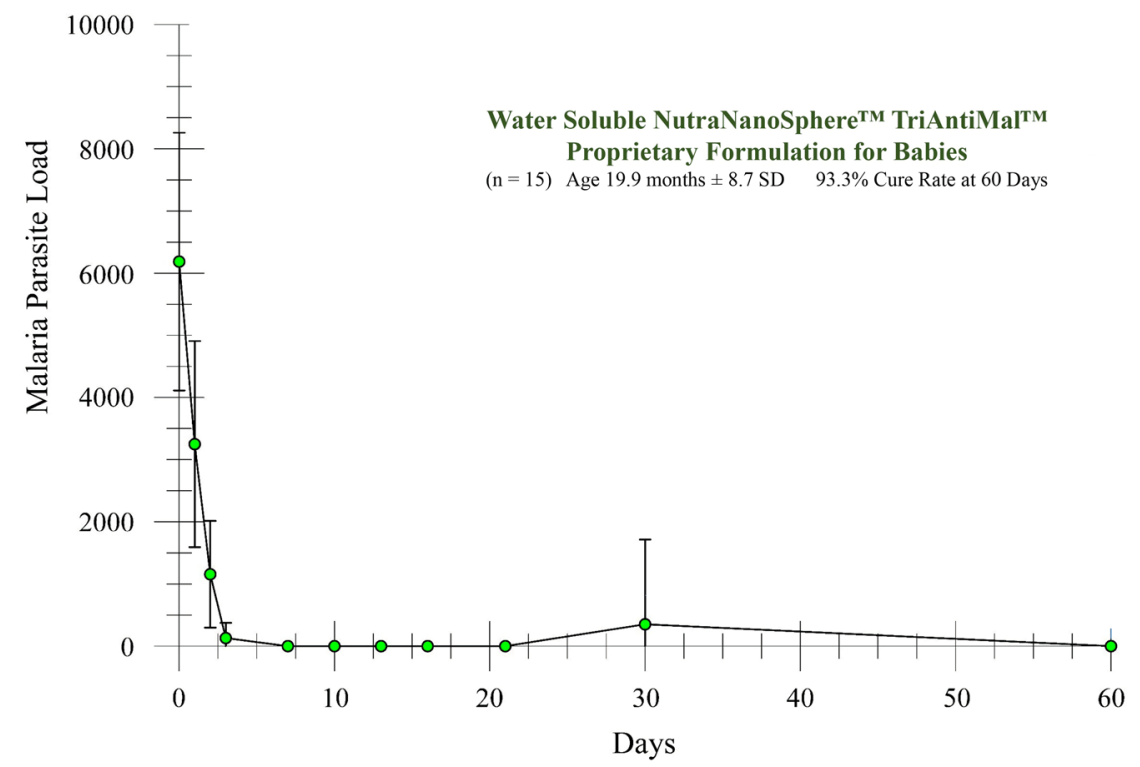

Figure 3. Water Soluble NutraNanoSphere ${ }^{\mathrm{TM}}$ Triantimal $^{\mathrm{TM}}$ Malaria Formulation for Babies. Parasite Free at Day 60 was $93.3 \%(n=15)$. The lone recurrance was seen at Day 30 as shown. SD bars are shown.

Table 1. Water-Soluble NutraNanoSphere ${ }^{\mathrm{TM}}$ TriAntiMal $^{\mathrm{TM}}$ proprietary formulation for babies. 93.3\% cure rate $(\mathrm{n}=15)$ through Day 60.

\begin{tabular}{|c|c|c|c|c|c|c|c|c|c|c|c|c|c|c|}
\hline LAB NO & Age (mo.) & Sex & MPL 0 & MPL 1 & MPL 2 & MPL 3 & MPL $7^{4}$ & MPL $10^{3}$ & ${ }^{3}$ MPL 13 & MPL 16 & MPL 21 & MPL 30 & MPL 60 & REMARKS \\
\hline $\mathrm{PF} / 021^{1}$ & 24 & Female & 7240 & 3160 & 1680 & 760 & 0 & 0 & 0 & 0 & 0 & 0 & 0 & Completed \\
\hline $\mathrm{PF} / 023$ & 24 & Male & 5120 & 2840 & 760 & 0 & 0 & 0 & 0 & 0 & 0 & 0 & 0 & Completed \\
\hline $\mathrm{PF} / 024$ & 12 & Male & 6440 & 3720 & 520 & 0 & 0 & 0 & 0 & 0 & 0 & 0 & 0 & Completed \\
\hline $\mathrm{PF} / 025^{2}$ & 12 & Female & 7640 & 4680 & 2120 & 320 & 0 & 0 & 0 & 0 & 0 & 0 & 0 & Completed \\
\hline $\mathrm{PF} / 027$ & 14 & Female & 6480 & 2920 & 760 & 0 & 0 & 0 & 0 & 0 & 0 & 0 & 0 & Completed \\
\hline $\mathrm{PF} / 028$ & 10 & Male & 9320 & 4200 & 1960 & 360 & 0 & 0 & 0 & 0 & 0 & 0 & 0 & Completed \\
\hline $\mathrm{PF} / 029$ & 24 & Female & 7240 & 3960 & 1720 & 0 & 0 & 0 & 0 & 0 & 0 & 0 & 0 & Competed \\
\hline $\mathrm{PF} / 030$ & 36 & Male & 10120 & 7840 & 3360 & 520 & 0 & 0 & 0 & 0 & 0 & 5280 & & Failed \\
\hline $\mathrm{PF} / 31$ & 24 & Male & 3160 & 720 & 0 & 0 & 0 & 0 & 0 & 0 & 0 & 0 & 0 & Completed \\
\hline $\mathrm{PF} / 32$ & 15 & Female & 4840 & 2160 & 400 & 0 & 0 & 0 & 0 & 0 & 0 & 0 & 0 & Completed \\
\hline $\mathrm{PF} / 33$ & 24 & Female & 6560 & 2920 & 840 & 0 & 0 & 0 & 0 & 0 & 0 & 0 & 0 & Completed \\
\hline $\mathrm{PF} / 34^{3}$ & 12 & Female & 7120 & 3760 & 1020 & 0 & 0 & 0 & 0 & 0 & 0 & 0 & 0 & Completed \\
\hline $\mathrm{PF} / 37^{3}$ & 9 & Male & 4120 & 2000 & 760 & 0 & 0 & 0 & 0 & 0 & 0 & 0 & 0 & Completed \\
\hline $\mathrm{PF} / 39$ & 24 & Female & 3120 & 1440 & 680 & 0 & 0 & 0 & 0 & 0 & 0 & 0 & 0 & Completed \\
\hline $\mathrm{PF} / 40$ & 35 & Female & 4280 & 2440 & 760 & 0 & 0 & 0 & 0 & 0 & 0 & 0 & 0 & Completed \\
\hline Mean & 19.9 & Male & 6187 & 3251 & 1156 & 131 & 0 & 0 & 0 & 0 & 0 & 352 & 0 & \\
\hline SD & 8.7 & $52 \%$ & 2074 & 1658 & 858 & 243 & 0 & 0 & 0 & 0 & 0 & 1363 & 0 & \\
\hline
\end{tabular}

${ }^{1} \mathrm{PF} / 22$ out of study never started; ${ }^{2} \mathrm{PF} / 26$ successfully completed 16 Day treatment but was lost to follow-up; ${ }^{3} \mathrm{PF} 35,36,38$ were lost to follow-up; ${ }^{4} \mathrm{MPL}$ clearance was $100 \%(15 / 15)$ by Day 7 .

during, and after the treatment, buffy coats were frozen at $-80^{\circ} \mathrm{C}$ from Days 0,5 , 10, 16, 30, and 60 and shipped on Dry Ice to the Cancer Research Institute of 
Table 2. DNA amplification probes-brief description.

\section{DNA Probe:}

ACTB - most abundant proteins in eukaryotic cells and are involved in cell motility, structure, and integrity. Negative control.

DEFB1 - an antimicrobial peptide implicated in the resistance of epithelial surfaces to microbial colonization.

IFNG - an antimicrobial peptide implicated in the resistance of epithelial surfaces to microbial colonization.

IL6-secreted by T cells and macrophages to stimulate immune response during infection and after trauma.

CD160-expression is tightly associated with peripheral blood NK cells and CD8 T lymphocytes with cytolytic effector activity.

DEFB119-antimicrobial peptide produced by neutrophils that protects tissues and organs from infection by a variety of microorganisms.

IL10-a cytokine synthesis inhibitory factor, which is an anti-inflammatory cytokine.

LAG3-inhibitory receptor expressed on activated CD8 and CD4 T cells (including Tregs) triggering signalling within Dendritic cells.

CD19-expressed during all phases of B cell development until terminal differentiation into plasma cells.

DEFB127-Defensins are cysteine-rich cationic polypeptides that are important in the immunologic response to invading microorganisms.

IL12A - acts on $\mathrm{T}$ and natural killer cells and has a broad array of biological activities.

NFKB1 - involved in the regulation of genes that impact not only immune responses but also cell proliferation, survival, and differentiation.

CD4-co-receptor of the T cell receptor (TCR) and assists the latter in communicating with antigen-presenting cells.

EGF-Epidermal growth factor is a growth factor that stimulates cell growth, proliferation, and differentiation by its receptor EGFR.

IL12B - expressed by activated macrophages, essential inducer of Th1 cells development for protection to intracellar pathogens.

PDCD1-Programmed Cell Death Protein 1, part of the immunoglobulin superfamily and is expressed on T cells and pro-B cells.

CD40-expressed on activated T cells, part of the TNF superfamily of molecules on antigen-presenting cells (APC).

GAPDH-Glyceraldehyde 3-phosphate dehydrogenase catalase the sixth step of glycolysis, initiation of apoptosis, ER to Golgi shuttling.

IL18 - proinflammatory cytokine that belongs to the IL-1 superfamily, produced by macrophages and other cells.

TGFA-TGF- $\alpha$ can be produced in macrophages, brain cells, and keratinocytes. TGF- $\alpha$ induces epithelial development.

CD8A - found on most cytotoxic T lymphocytes that mediates efficient cell-cell interactions within the immune system.

HBD - Haemoglobin subunit delta is a protein that in humans. Negative control.

IL2-promotes the differentiation of T cells into effector T cells and into memory T cells helping the body fight off infections.

CD8B-found on most cytotoxic T lymphocytes that mediates efficient cell-cell interactions within the immune system.

IFNA1 - produced by macrophages and has antiviral activity.

IL4 - cytokine that induces differentiation of naive helper T cells (Th0 cells) to Th2 cells.

DEFA1 - antimicrobial and cytotoxic peptides thought to be involved in host defense.

IFNB1 - antiviral, antibacterial, and anticancer properties.

IL5-cytokine that acts as a growth and differentiation factor for both B cells and eosinophils.

Table 3. DNA Amplification markers for chilren (Days 0 - 730) and Babies (Days 0 - 60).

\begin{tabular}{|c|c|c|c|c|c|c|c|c|}
\hline \multicolumn{9}{|c|}{ DNA Amplification Markers for Children Days $0-730^{1}$} \\
\hline \multicolumn{9}{|c|}{ Normalized to Day 0 Values ${ }^{2}$} \\
\hline & & & & & & & & Changes over time \\
\hline DNA Probe & Day 0 & Day 5 & Day 10 & Day 16 & Day 30 & Day 60 & Day 730 & Blanks mean no significant changes \\
\hline АСТВ & 100 & 117 & 101 & 120 & 115 & 108 & 125 & \\
\hline DEFB1 & 100 & 81 & 106 & 92 & 103 & 104 & 101 & \\
\hline IFNG & 100 & 120 & 92 & 114 & 112 & 120 & 163 & INFG $>20 \%$ Day 5 to $<28 \%$ Day $10 ; 63 \%>$ Day 730 \\
\hline IL6 & 100 & 83 & 102 & 107 & 107 & 102 & 115 & IL6 decreased 17\% Day 5 \\
\hline $\mathrm{CD} 160$ & 100 & 81 & 96 & 106 & 100 & 109 & 110 & CD160 decreased $19 \%$ \\
\hline DEFB119 & 100 & 127 & 101 & 116 & 119 & 114 & 128 & DEFB119 increased $27 \%$ on Days 5 and 730 \\
\hline
\end{tabular}




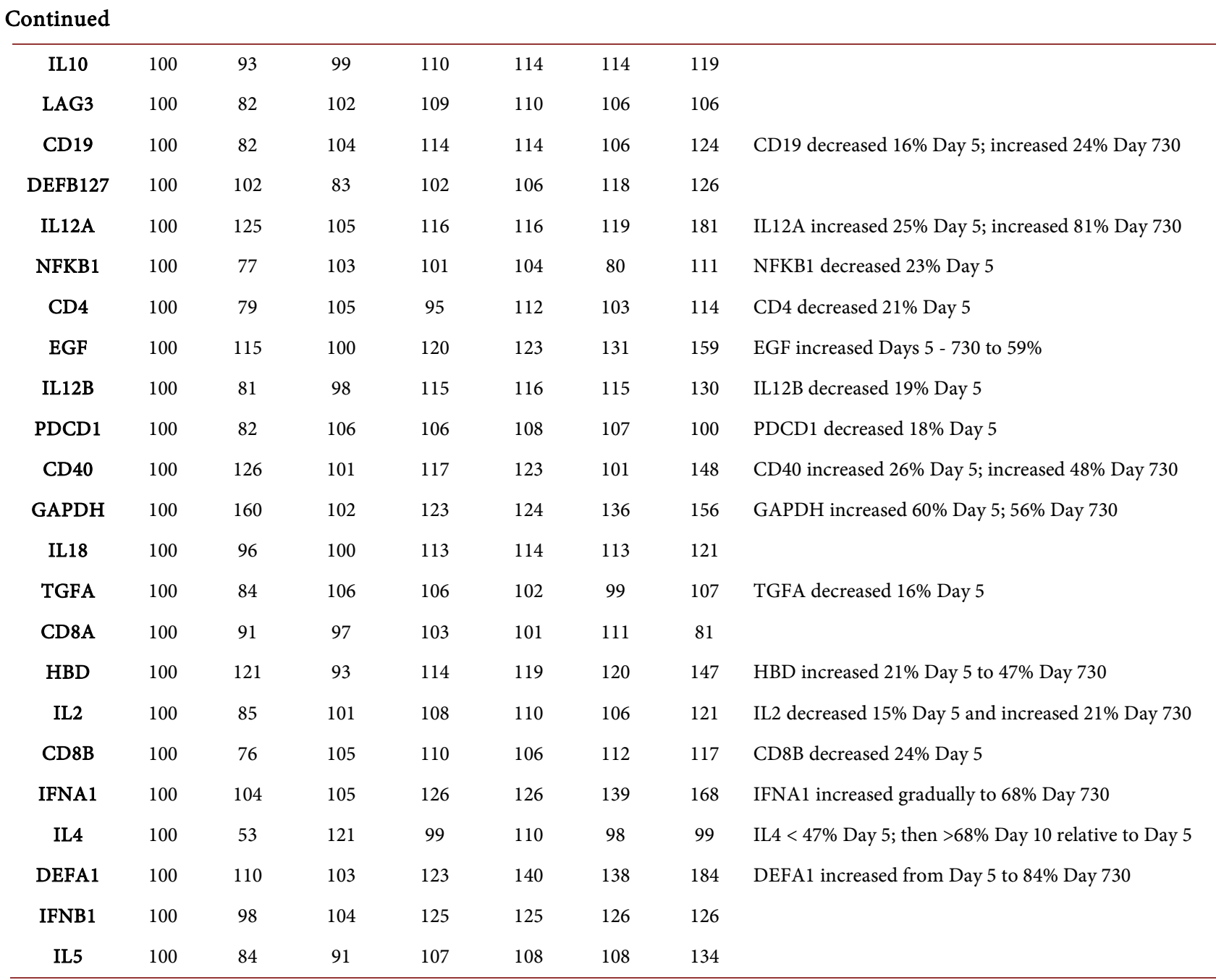

${ }^{1}$ Day 0 to $60(\mathrm{n}=16)$ Day $730(\mathrm{n}=13) \mathrm{SD} \pm 2-4{ }^{2}$ For example, 117 means $17 \%$ increase.

Table 4. Summary DNA amplification markers for children Days $0,5,10,16,30,60,730^{1}$.

\begin{tabular}{cc}
\hline Markers positive (Day 5 \& later) & Markers Neutral, No Change \\
\hline IL12A++ & ACTB \\
EGF++ & DEFB1 \\
DEFA1+ & DEFB127 \\
DEFB119+ & IL5 \\
CD40+ & L10 \\
GAPDH+ & IL18 \\
HBD+ & CD8A \\
IFNA1+ & IFNB1 Neutral then+ \\
IFNG+ & \\
& Markers Negative Day 5 \\
Markers Negative, Positive (Days 10 \& later) & TGFA- \\
CD8B- then+ & IL6- \\
CD19- then+ & CD4- \\
IL2 - then+ & CD160- \\
IL4- then+ & PDCD1- \\
IL12B- then+ & NFKB- \\
LAG3 - then+ & \\
\hline
\end{tabular}

${ }^{1}$ Children 0 to 60 days $(n=16)$; Day $730(n=13) \pm 2-4$ SD. 
Table 5. Summary DNA Amplification markers for babies Days 0, 16, 30, 60.

\begin{tabular}{|c|c|c|c|c|c|}
\hline \multicolumn{6}{|c|}{ BABIES Days $0,16,30,60^{1}$} \\
\hline & \multicolumn{4}{|c|}{ Normalized to Day 0 Values } & \multirow[b]{2}{*}{ NOTES on Changes } \\
\hline & Day 0 & Day 16 & Day 30 & Day 60 & \\
\hline АСТВ & 100 & 103 & 99 & 88 & \\
\hline DEFB1 & 100 & 96 & 90 & 90 & \\
\hline IFNG & 100 & 100 & 73 & 89 & IFNG dropped $27 \%$ by Day 30 \\
\hline IL6 & 100 & 102 & 103 & 100 & \\
\hline CD160 & 100 & 106 & 106 & 93 & \\
\hline DEFB119 & 100 & 112 & 107 & 100 & \\
\hline IL10 & 100 & 109 & 92 & 101 & \\
\hline LAG3 & 100 & 111 & 102 & 92 & \\
\hline CD19 & 100 & 112 & 90 & 86 & \\
\hline DEFB127 & 100 & 127 & 104 & 106 & DEFB127 increase 27\% Day 16 \\
\hline IL12A & 100 & 109 & 111 & 94 & \\
\hline NFKB1 & 100 & 114 & 118 & 81 & NFKB1 increased $4 \%$ by Day 16 \\
\hline $\mathrm{CD} 4$ & 100 & 104 & 120 & 102 & CD 4 increased $20 \%$ by Day 30 to decrease $18 \%$ by Day 60 \\
\hline EGF & 100 & 123 & 110 & 77 & EGF increased 23\% Day 16 to decrease to decrease by $46 \%$ Day 60 \\
\hline IL12B & 100 & 118 & 113 & 88 & \\
\hline PDCD1 & 100 & 105 & 113 & 95 & \\
\hline $\mathrm{CD} 40$ & 100 & 122 & 102 & 80 & CD 40 increased $22 \%$ by Day 16 to decrease $42 \%$ by Day 60 \\
\hline GAPDH & 100 & 107 & 98 & 84 & GAPDH decreased $16 \%$ by Day 60 \\
\hline IL18 & 100 & 109 & 118 & 87 & IL18 increased $18 \%$ day 30 to decrease $31 \%$ from Day 30 to day 60 \\
\hline TGFA & 100 & 110 & 99 & 94 & \\
\hline CD8A & 100 & 105 & 79 & 97 & CD8A dropped $21 \%$ by Day 30 \\
\hline HBD & 100 & 93 & 93 & 101 & \\
\hline IL2 & 100 & 111 & 94 & 92 & IL2 increase $11 \%$ by Day 16 to decrease $19 \%$ by Day 60 \\
\hline $\mathrm{CD} 8 \mathrm{~B}$ & 100 & 110 & 105 & 88 & CD8B increased $10 \%$ day 16 to decrease $22 \%$ by Day 60 \\
\hline IFNA1 & 100 & 127 & 99 & 83 & IFNA1 increased $27 \%$ Day 16 to decrease $44 \%$ by Day 60 \\
\hline IL4 & 100 & 102 & 108 & 102 & \\
\hline DEFA1 & 100 & 122 & 98 & 74 & DEFA1 increase $22 \%$ by Day 16 to decrease $48 \%$ by Day 60 \\
\hline IFNB1 & 100 & 112 & 104 & 89 & \\
\hline IL5 & 100 & 125 & 82 & 89 & IL5 increased $25 \%$ Day 16 to decrease $36 \%$ by Day 60 \\
\hline
\end{tabular}

${ }^{1}$ Babies $0,16,30,60$ days $(\mathrm{n}=14) \pm 2-4$ SD.

West Tennessee for storage at $-80^{\circ} \mathrm{C}$. Multiple aliquoting into three equal portions and refrozen at $-80^{\circ} \mathrm{C}$. One preparation was used to process 25 of these patients at random for the complementary DNA (cDNA) preparation of 16 patients for DNA amplification analysis. The cure rate for the 31 Buffy Coat children 
Table 6. Summary DNA amplification markers for babies at Days $0,16,30,60^{1}$.

\begin{tabular}{cc}
\hline Markers positive (Days $\mathbf{1 6}$ and 30) & Markers Neutral, No Change \\
\hline IL12A+ & ACTB \\
IL12B+ & DEFB1 \\
EGF+ & IL2 \\
DEFB127+ & IL4 \\
DEFA1+ & IL6 \\
DEFB119+ & IL10 \\
CD40+ & IL18 \\
IFNA1+ & IFNB1 \\
NFKB1+ & CD4 \\
Markers positive Day 16 then Negative Day 30 & CD160 \\
GAPDH+ then- & LAG3 \\
CD8B+ then- & PDCD1 \\
CD19+ then- & TGFA \\
IL5+ then- & CD8A \\
& HBD \\
& INFG Neutral then-Day 30/60
\end{tabular}

${ }^{1}$ Babies $0,16,30,60$ days $(\mathrm{n}=14) \pm 2-4$ SD.

was $28 / 31(90.2 \%)$ and was included with all the children identical to the overall survival rate made up the 101/112 (90.2\%) children.

Buffy coats were obtained from the 15 babies to date, and 14 were processed for the cDNA amplification and DNA gene expression study.

QIAzol/RNeasy procedure (Quiagen.). RNA was prepared from each buffy coat sample following the manufacturer's instructions (Qiagen, USA). Briefly, $300 \mu \mathrm{l}$ of buffy coat was vortexed with the QIAzol reagent. After a series of buffer extractions and high-speed (10,000 xg) centrifugation steps, the lysate was passed through the RNAeasy MiniElute silica gel membrane column. The bound RNA was eluted with RNase/DNase free water, high speed centrifugation of the column resulted in $50 \mu \mathrm{l}$ of final RNA product. The RNA yields were $0.1-0.3$ $\mathrm{pg} / \mu \mathrm{l}$ using the Quibit RNA BR assay and the DeNovix QFS Fluorimeter.

Reverse DNA Transcription for the complementary DNA production. A $1.55 \mu \mathrm{l}$ of RT Master Mix (Fluidigm) was added to $4 \mu \mathrm{l}$ of patient RNA samples and cDNA was transcribed following the manufacturer's protocol. Duplicate plates were processed for 16 children, 13 Day 730 children, and 14 babies. These plates were stored at $-80^{\circ} \mathrm{C}$ and shipped overnight on dry ice to the Harvard Molecular genetics Core Facility at Boston Children's Hospital.

Gene expression and detection. cDNA was preamplified with 20 cycles of PCR using Fluidigm's preamplification Master Mix and protocol for Delta Gene Assays. Preamplified, EXOI-cleaned and diluted (5-fold) samples were run in the Biomark system for RT-qPCR following Fluidigm's Delta Gene protocol for 29 assays.

Table 2 shows the 29 primer designs used to detect gene expression levels. The choice of these primer markers was based on a survey of possible markers associated with malaria infection. 


\section{Results}

\subsection{Malaria Parasite Load (MPL) during and after Treatment for Babies and Children}

The $P$. falciparum Malaria Parasite Load (MPL) clearance curve with standard deviation (SD) bars included the original children and the buffy coat children of the $P$. falciparum-free children is shown in Figure 2 . In the combined children study $(\mathrm{n}=121)$, the ages ranged between 2.5 and 15 years old for an average age of $8.4 \pm 3.6 \mathrm{SD}(\mathrm{n}=110)$ for the cured children and $8.3 \pm 2.4(\mathrm{n}=11)$ for the recurrent children. The average MPL at day zero was about 22,000 for both the cured and recurrent patients. The patient groups were almost equally divided (Males $52.8 \pm 5.8 \mathrm{SD} n=121$ ) between males and females. The cure rate in the Original Children's study was $90.2 \%$ and decreased $5.1 \%$ by Day $730(n=51)$.

Table 1 presents the Data from the baby studies to date. The percentage cured by day 60 was $93.3 \%$. P . falciparum clearance rate at 7 days into the 16-day treatment was $100 \%$. The average age was 19.9 months $\pm 8.7 \mathrm{SD}$, and $47 \%$ were males. Figure 3 is a graphic representation of Table 1 showing the rapid clearance of the $P$. falciparum in babies with $93.3 \%$ parasite-free at 60 days.

\subsection{The DNA Markers}

Table 2 shows the DNA markers used in this initial study. These markers were chosen because of their possible association with malaria. These DNA amplification markers were grouped into Interleukins, Cytokines, Interferons, Defensins, and various markers for inflammation. The term "neutral" used throughout refers to a value not changing from the Day 0 values of each of the DNA markers. The DNA marker term "negative" means the DNA was down regulated. The DNA marker term "positive" means the DNA was up regulated. All DNA marker values were standardized to their respective Day 0 values.

\subsection{Children Days 0 - 730}

In Table 3, DNA marker results from 16 buffy coat samples were obtained as described in the Materials and Methods section. Buffy coats and sera were obtained from children at days $0,5,10$, and 16 during treatment and days 30, 60, and 730 after treatment. The DNA values were normalized to Day 0 and the relative percentages were obtained. For example, a mean 117 value relative to Day 0 being $100 \%$ would signify a $17 \%$ increase over the Day 0 control value for each DNA probe. For Day 0 - 60, 16 patients were used to obtain the mean and Standard Deviations (SD), which averaged $\pm 2-4$ SD. The comment section of Table 3 describes some the more notable changes during and after treatment.

A summary Table 4 of the DNA markers from Table 3 for the children centered on the relative percentage changes at Day 5. These data included markers positive at Day 5 and later, markers negative at Day 5 then positive by Day 10 and later, markers neutral without significant change throughout, and markers negative at Day 5 onward. 
The two most positive Markers included IL12A and EGF. For the Interleukins, IL2, IL4, and IL12B were negative at Day 5 and were positive by Day 10 and beyond relative to Day 0 . The Interleukins were neutral and did not change included IL10 and IL18. IL6 was negative at Day 5 and subsequently became neutral.

Interestingly, two defensins, DEFA1 and DFB119, were positive, while the other two defensins, DEFB1 and DEFB127, remained neutral.

CD40 was positive, while CD19 became positive by Day 10. CD4 and CD160 were negative at Day 5 and remained negative. CD8A was neutral, while CD8B was negative at Day 5, then became positive by Day 10.

Concerning the Interferons, Interferon Alpha (INFA1) and INF Gamma (INFG) were positive at Day 5 onward. Interferon Beta (INFB1) was neutral at Day 5 and then became positive.

\subsection{Babies Days 0 - 60}

Table 5 presents the mean DNA marker results from 14 buffy coat samples, obtained from cured babies as described in the Materials and Methods section. Buffy coats and sera were obtained from babies at days $0,16,30$, and 60 during and after the 16-day treatment. Instead of gel caps, the babies were given the water-soluble NutraNanoSpheres ${ }^{\mathrm{TM}}, 7-10 \mathrm{~nm}$ diameter micellized drops directly into their milk bottles daily.

In Table 6 is a summary of the DNA markers from Table 2 for the babies centered on the relative percentage changes at Days 16 and 30. These data included Markers positive at Days 16 and 30, Markers positive at Day 16 then negative by Day 30, and Markers neutral without significant change throughout.

For the Interleukins, IL12A and IL12B were positive at Days 16 and 30. IL5 was positive at Day 16 then negative by Day 30. IL2, IL6, IL10, IL18 and were neutral on Day 16 - 60.

Interestingly, three Defensins, DEFA1, DFB119, and DEFB127, were positive, while DEFB1remained neutral.

CD40 was positive at Days 16 and 30 but was negative by Day 60. CD8B and CD19 were positive on Day 16 and negative by Day 30. CD4 and CD160 were neutral throughout.

Concerning the Interferons, Interferon Alpha (INFA1) and INF Gamma (INFG) were positive at Day 16 onward. Interferon Beta (INFB1) was neutral at Day 5 and then became positive.

\subsection{Summary of DNA Amplification Markers: Children vs. Baby Comparisons}

Table 7 shows the comparisons between the DNA amplification markers between children and the babies. INFG was positive throughout for the children, but not the babies. The babies showed positive throughout for IL12B, DEFB127, and NFKB1, but the children were not positive for any of these markers. For the children, TGFA, IL6, CD4, CD160, PDCD1, and NFKB1 were negative at Day 5, 
Table 7. Summary DNA Amplification markers children vs. babies' comparisons at Day 16.

\begin{tabular}{lc}
\hline \multicolumn{2}{c}{ Markers found in one and not the other age group } \\
\hline \multicolumn{1}{c}{ Children Days 0, 5, 10, 16, 30, $60^{2}, \mathbf{7 3 0}^{\mathbf{3}}$} & Babies Days 0, 16, 30, 60 \\
\hline POSITIVE: INFG+ & IL12B+; DEFB127+; NFKB1+ \\
NEGATIVE:TGFA; IL6; CD4; CD160; PDCD1;NFKB & NONE \\
NEGATIVE THEN POSITIVE: CD8B; CD19; IL2; IL4; IL12B; & NONE \\
LAG3; IFNB1 & \\
POSITIVE THEN NEGATIVE: NONE & CD8B; CD19; IL5; GAPDH \\
\hline
\end{tabular}

${ }^{1}$ Markers not listed were in the neutral, No change group; ${ }^{2}$ Children 0 to 60 days $(\mathrm{n}=16) ;{ }^{3}$ Day $730(\mathrm{n}=$ 13); ${ }^{4}$ Babies $0,16,30,60$ days $(\mathrm{n}=16)$; ${ }^{5}$ IFNB1 Neutral then+.

and remained negative or neutral throughout. The babies were neutral for these markers, except for the positive NFKB1. The children showed positive CD8B, CD19. IL2, IL4, IL12B, LAG3, and INFB1 (neutral to positive) after a negative Day 5. In contrast, the babies did not show the negative to positive transition for these markers. The babies, however, did reveal positive to negative reduction for the DNA makers CD8B, CD19, IL5, and GAPDH. In contrast, the children did not show the positive to negative transition for these markers.

\section{Discussion}

IL12A and Il12B. Life-threatening complications in severe childhood malaria include hyperparasitemia, hypoglycemia, cerebral malaria, respiratory distress, and severe malaria anemia [3] [4]. There are strong associations between polymorphisms in the genes of IL12A and IL12RB1 and protection from SMA in Kenyan children, suggesting that human genetic variants of IL12 related genes may significantly contribute to the development of anemia in malaria patients [5]. Treatment with IL12 corrects malarial anemia [6] [7] [8]. In the children (Table 3 and summary Table 4) and in the babies during treatment (Table 5 and summary Table 6), gene amplification of IL12A and IL12B were significantly positive.

Epidermal growth factor (EGF) is a growth factor that stimulates cell growth, proliferation, and differentiation by binding to its receptor EGFR. The elevation of both EGF and IL12 (summary Table 4 and Table 6) in the children and babies has a positive prognostic significance [9].

For the other Interleukins in children, IL2, IL4, and IL12B were negative at Day 5 and were positive by Day 10 and beyond relative to Day 0. IL6 was negative (downregulated) at Day 5 and subsequently became neutral (expression remained unchanged). IL2 is important for the proliferation of T and B lymphocytes, especially among young children. The receptor for this cytokine is a heterotrimeric protein complex whose gamma chain is also shared by Interleukin 4 (IL4) and Interleukin 7 (IL7) [10]. IFN-gamma levels were elevated in patients with complicated malaria in the initial stage of the disease before treatment compared to the levels found with uncomplicated malaria, while the IL4 levels were elevated 7 days after treatment [11]. 
Interleukins that did not change in expression level included IL10 and IL18. Interleukin-18 (IL18) is a potent proinflammatory cytokine that induces interferon-Gamma (IFNG) production from Th1 cells, NK cells and activated macrophages, particularly in the presence of IL12 [12]. However, the IL-18 production was neutral for the children and babies with minimal elevation of Interferon gamma (IFNG). IL18 is capable of inducing IL4 and IL13 production in T cells, NK cells, mast cells, and basophils. IL18 plays a key role in inducing severe malaria through a pathway of elevating IFNG [12]. Neither one of these proinflamatory interleukins were elevated in the children and babies, thus minimizing the severe malaria proinflamatory pathway [11] [12].

Humoral immunity develops in the spleen during blood-stage plasmodial infection. This elicits parasite-specific IgM and IgG, which control parasites and protect against malaria. IL-6 promotes $\mathrm{CD}^{+}{ }^{+} \mathrm{T}$-cell activation and B-cell responses during blood-stage plasmodial infection, which encourages parasite-specific antibody production [13]. For both the children and babies, IL6 gene expression was unchanged during and after treatment. Immunity to malaria in malaria patients had a characteristically strong pro-inflammatory/Th1 signature. Pro-inflammatory responses and tolerance to $P$. falciparum is believed to wane with time in the absence of exposure to $P$. falciparum infection [13]. Interestingly, IL-12, alpha interferon- Alpha (IFNA1), and IFNG levels have been reported lower in children with severe malaria, while IL10 levels higher [14], which is the opposite of our measurements for both Children (Table 3 and Table 4) and Babies (Table 5 and Table 6).

At day 5 into the TriAntiMal ${ }^{\mathrm{TM}}$ treatment, the CD8B and CD19 DNA amplification markers were negative (downregulated), then became positive (upregulated) by Day 10 for both the children and babies. Cerebral malaria (CM) is one the major complications occurring during malaria infection. While the mechanisms leading to this syndrome are still not completely understood, depletion of $\mathrm{CD}^{+}$dendritic cells at the beginning of infection prevented experimental cerebral malaria (ECM) development and death [15].

B-cells are essential in immunity against malaria. In new-borns, naïve B-cells play a major role in recognizing $P$. falciparum. In adults, the high proportion of $P$. falciparum specific memory B-cells suggests they play a major role against malaria. CD19 positive B cells confer protection against cerebral malaria in semi-immune rodent model. CD19 positive B cells are determinants in protective mechanism of semi-immune mice against ECM possibly via modulatory IL-10 for pathogenic IFN- $\gamma$ production [16].

At five days into the TriAntiMal ${ }^{\mathrm{TM}}$ treatment of the children, the IFNA1 and CD40 genes expression increased significantly (statistical test; $p$ value) even after 730 days. In the babies, both levels peaked at Day 16 and subsequently decreased through Day 60. IFNA1 and CD40 play a significant role in malaria. CD40 is a modulator of adaptive immunity, because elevated CD40 levels appear early after malaria infection in the blood and has a role in innate IFNA1 responses and disease control [17] [18]. The costimulatory molecule CD40 enhances immunity 
through several distinct roles in $\mathrm{T}$ cell activation and $\mathrm{T}$ cell interaction with other immune cells. In a mouse model of immunity to liver stage plasmodial infection, CD40 had been shown to be critical for the full maturation of liver dendritic cells, accumulation of $\mathrm{CD} 8(+) \mathrm{T}$ cells in the liver, and protective immunity [19].

In studies like reported here, Glucose-6-phosphate dehydrogenase (GAPDH) is usually used as an internal marker for monitoring gene expression or in some situations used to normalize the gene expression levels. We use the values at Day zero to normalize our data. However, GAPDH is important in the control of oxidant stress in erythrocytes, the host cells for $P$. falciparum. Mutations in this enzyme produce $\mathrm{X}$-linked deficiency states associated with protection against malaria, notably in Africa where the A form of GAPDH deficiency is widespread [20]. In the children, GAPDH was positive throughout, while the babies were positive at Day 16 and then became negative by Day 30. Therefore, it appears a GAPDH deficiency

In Table 7, the comparisons between the children and the babies' immunologic genes expression showed many similarities with some exceptions. At the Day 16 comparisons, the children were uniquely positive for INFA, INFB1, and INFG in contrast to the babies, which showed the only positive defensin, DEFB 127, even though DEFA1 was positive for both, The babies at the end of the 16-day treatment were either no changed in expression or positive (upregulated) by Day 30 for all the markers, except CD8B, CD19, and GAPDH, which were positive by Day 16 and the negative by Day 30/60. None of the babies started out negative at Day 16, then showed positive DNA amplification values. However, there were positive values for the children at Day 16, which became neutral or negative by Day 60 as shown in Table 7. There were at least six more genes that were negative for the children when compared to the babies.

One of the most interesting results was the upregulation of the defensins genes in both the children and babies. In the children, while DEFB1 and DEF127 remained neutral (unchanged), significantly upregulated (statistical test, $p$ value) were measured for DEFA1 and DEFB119, even at Day 730 in the cured children. The babies uniquely showed upregulation for DEF127 and DEFA1, as also for the children, at Day 16, which downregulation occurred through Day 60. DEFB1 was unchanged in the babies. To these authors knowledge, there have not been any papers published on Defensins AND Malaria (PubMed.com). Furthermore, the innate activity of defensins has been thought to be restricted to antiviral and antibacterial activity. The mechanism(s) of how they would operate against parasites internally is not clear. Based on the intracellular destruction of bacteria in neutrophils containing defensin granules, there may be the possibility that defensins can operate within the liver and erythrocytes infected with the parasites. Furthermore, the significant upregulation ( $\mathrm{p}$ value) of the immune regulatory genes, e.g. DEFA1 in children at Day-16 through day-730, may be showing immunological memory among defensins against $P$. falciparum.

The unique, common biochemical structure of defensins contains six cyste- 
ines and three intramolecular disulfide bridges, consisting of 18 - 45 amino acids, and are classified into three different subgroups: human $\alpha, \beta$, and mouse $\theta$ defensins [21] [22] They kill phagocytosed bacteria, for example in neutrophil granulocytes, by binding to the microbial cell membrane, and forming pore-like membrane defects that osmotically compromise the microbe [23] allowing efflux of essential ions and nutrients. They are seen across the vertebrate lineage ranging from bony fish to human [24] and are found in plants [25].

DEFA1 genes encode human neutrophil peptides (HNP) 1 - 3 and are involved in directly killing pathogens [26] [27]. HNP1-3 also is functionally associated with innate immunity and infections [28] [29].

Beta-defensins, such as DEFB1, DEFB119, and DEFB127 presented here, are antimicrobial peptides that protect tissues and organs from infection by a variety of microorganisms like the DEFA1 Alpha Defensins described above [30] [31] [32] [33]. A specific $\beta$-defensin called tracheal antimicrobial peptide $(T A P)$ is found along the entire length of conducting airways [34]. In the lung, the $\beta-1$ TAP defensin prevents infection by virulent or opportunistic pathogens. In patients with cystic fibrosis (CF), the TAP is inactivated by high salt concentrations in the respiratory mucosa [34]. This allows development of respiratory tract infections with opportunistic pathogens such as Pseudomonas aeruginosa. Defensins also prevent the influenza virus from entering target cells. Influenza hemagglutinins are necessary for binding the virus to the target cell. Defensins render the virus noninfectious by cross-linking hemagglutinins, which prevents the normal interaction between the virus and the host cell membrane [32] [35]. Most of the cellular function alpha and beta defensins are housed in the granules of neutrophils to help fight bacterial and viral infections [36] [37]. Beta defensins inhibit HIV replication and selectively protects primary $\mathrm{CD}^{+} \mathrm{T}$ cells infected with HIV-1 [38]. However, there is no evidence from the literature that defensins protect against malaria parasites and show immunological memory. We may be reporting for the first time process that accentuates the production of defensins, which may have immunological memory due to the upregulation of specific immune regulation genes long after parasite clearance in children (Table 3).

\section{Conclusions}

We present a result of chemotherapy that seems to enhance the immunity of infected patients treated with the combination therapy of TriAntiMal ${ }^{\mathrm{Tm}}$. This model starts with a malaria infection, a treatment to remove the parasite load and an immunity to assure the malaria cannot return, regardless of a person being bitten again. For the first phase to determine the immunologic processes involved, we measured the gene expression response before, during, and after therapy. The results show all aspects of the humoral, cellular, and innate immunity being involved in long-term immunity against $P$. falciparum. Our future studies will analyze the serum samples to determine the actual soluble, protein-based im- 
mune entities, such lymphokines, cytokines, Interferons, Defensins, and specific antibodies and antibody types against $P$. falciparum which appear in the bloodstream during the steps to immunity and see how they correlate with the DNA activation data in this paper.

Finally, we need to address the whole process of how we cure malaria. Waiting for the parasite to be manifested in the blood before treatment begins may not be the correct way to treat malaria. Our treatment is safe and efficacious, may justify treating individuals indigenous to a malaria infested country, since liver and other organs may harbor the P. falciparum. Regardless, if we are going to make a major impact on ridding the world of this devastating disease, we must be willing to focus on a treatment that is curative, one-series treatment, safe, and inexpensive. This research also introduces the hope of curing bacterial and viral diseases, cancer and other life-threatening diseases.

\section{Acknowledgements}

This research was funded by the Cancer Research Institute of West Tennessee with Henry Respess, the Shumard Family Fund, and Carter Foundation. This work began 14 years ago in collaboration between Dr. \& Mrs. Thornthwaite with Roberta Edwards, Dr. Wildert Charles and the Ministry of Health in Haiti, in treating babies, children and adults for $P$. falciparum. We thank Professor Alebiosu, Chairman of the UNIOSUN HREC Committee, and the College of Health Sciences at the Osun State University in Osogbo, Nigeria. Special thanks to the doctors, nurses and staff who were successful in maintaining compliance to the protocol of the study presented herein. We thank Dr. Pat Evans and Seth Thibado for their statistical analyses and graphics, Patty O'Neal's laboratory work, and Dr. Tony Kirk, Edra Shalla and Bonita Thornthwaite for their careful proof reading of this manuscript. We thank Chrystal Mavros for directing the Harvard Molecular Genetics Core Facility at Boston Children's Hospital for performing the Preamplification of cDNA, supplied by the Cancer Research Institute of West Tennessee from the buffy coat preparations from Dr. Akanni's laboratory, and running the BioMark Delta Gene Assays. Special thanks go to Dr. Lothar Haegele of X-Labs (Singapore) for supplying the NutraNanoSpheres ${ }^{\mathrm{TM}}$ preparations for this study. We thank Katy Richards-Hrdlicka from Fluidigm for her very helpful assistance to Dr. Thornthwaite in choosing the DNA gene expression probes. Special thanks to Dr. Steve Philips, Dr. Larry Loomis, and Mr. Berny Dohrmann for their scientific input and encouragement through a very difficult process. This paper is dedicated in the Memory of Roberta Edwards, who believed in our work and applied her Christian virtues in helping us heal the babies, children, and adults of Haiti of Malaria.

\section{Conflicts of Interest}

The authors declare no conflicts of interest regarding the publication of this paper. 


\section{References}

[1] http://www.who.int/malaria/publications/world_malaria_report_2014/report/en/

[2] http://www.malariavaccine.org/malaria-and-vaccines/first-generation-vaccine/rtss

[3] Perkins, D.J., Were, T., Davenport, G.C., Kempaiah, P., Hittner, J.B. and Ong'echa, J.M. (2011) Severe Malarial Anemia: Innate Immunity and Pathogenesis. International Journal of Biological Sciences, 7, 1427-1442. https://www.ncbi.nlm.nih.gov/pubmed/22110393

[4] McDevitt, M.A., Xie, J., Gordeuk, V. and Bucala, R. (2004) The Anemia of Malaria Infection: Role of Inflammatory Cytokines. Current Hematology Reports, 3, 97-106. https://www.ncbi.nlm.nih.gov/pubmed/14965485?report=docsum\&format=text

[5] Zhang, L., Prather, D., Vanden Eng, J., Crawford, S., Kariuki, S., ter Kuile, F., Terlouw, D., Nahlen, B., Lal, A.A., Slutsker, L., Udhayakumar, V. and Shi, Y.P. (2010) Polymorphisms in Genes Ofinterleukin 12 and Its Receptors and Their Association with Protection against Severe Malarial Anaemia in Children in Western Kenya. Malaria Journal, 9, 87. https://www.ncbi.nlm.nih.gov/pmc/articles/PMC2858737/

[6] Chang, K.H. and Stevenson, M.M. (2004) Malarial Anaemia: Mechanisms and Implications of Insufficient Erythropoiesis during Blood-Stage Malaria. International Journal for Parasitology, 34, 1501-1516. https://doi.org/10.1016/j.ijpara.2004.10.008

[7] Mohan, K. and Stevenson, M.M. (1998) Interleukin-12 Corrects Severe Anemia during Blood-Stage Plasmodium Chabaudi AS in Susceptible A/J Mice. Experimental Hematology, 26, 45-52.

[8] Chaisavaneeyakorn, S., Othoro, C., Shi, Y.P., Otieno, J., Chaiyaroj, S.C., Lal, A.A. and Udhayakumar, V. (2003) Relationship between Plasma Interleukin-12 (IL-12) and IL-18 Levels and Severe Malarial Anemia in an Area of Holoendemicity in Western Kenya. Clinical and Diagnostic Laboratory Immunology, 10, 362-366. https://doi.org/10.1128/CDLI.10.3.362-366.2003

[9] MacMullin, G., Mackenzie, R., Lau, R., Khang, J., Zhang, H., Rajwans, N., Liles, W.C. and Pillai, D.R. (2012) Host Immune Response in Returning Travellers Infected with Malaria. Malaria Journal, 11, 148.

https://www.ncbi.nlm.nih.gov/pmc/articles/PMC3586951/

[10] Farrington, L., Vance, H., Rek, J., Prahl, M., Jagannathan, P., Katureebe, A., Arinaitwe, E., Kamya, M.R., Dorsey, G. and Feeney, M.E. (2017) Both Inflammatory and Regulatory Cytokine Responses to Malaria are Blunted with Increasing Age in Highly Exposed Children. Malaria Journal, 16, 499.

https://doi.org/10.1186/s12936-017-2148-6

[11] Tangteerawatana, P., Pichyangkul, S., Hayano, M., Kalambaheti, T., Looareesuwan, S., Troye-Blomberg, M. and Khusmith, S. (2007) Relative Levels of IL4 and IFN-Gamma in Complicated Malaria: Association with IL4 Polymorphism and Peripheral Parasitemia. Acta Tropica, 101, 258-265.

https://www.sciencedirect.com/science/article/abs/pii/S0001706X0700071X?via\%3D ihub

[12] Kojima, S., Nagamine, Y., Hayano, M., Looareesuwan, S. and Nakanishi, K. (2004) A Potential Role of Interleukin 18 in Severe Falciparum Malaria. Acta Tropica, 89, 279-284.

[13] Howland, S.W., Claser, C., Poh, C.M., Gun, S.Y. and Rénia, L. (2015) Pathogenic CD8+ T Cells in Experimental Cerebral Malaria. Seminars in Immunopathology, 37, 221-231. https://doi.org/10.1007/s00281-015-0476-6 
[14] Luty, A.J., Perkins, D.J., Lell, B., Schmidt-Ott, R., Lehman, L.G., Luckner, D., Greve, B., Matousek, P., Herbich, K., Schmid, D., Weinberg, J.B. and Kremsner, P.G. (2000) Low Interleukin-12 Activity in Severe Plasmodium Falciparum Malaria. Infection and Immunity, 68, 3909-3915. https://www.ncbi.nlm.nih.gov/pmc/articles/PMC101666/

[15] Fernandez-Ruiz, D., Lau, L.S., Ghazanfari, N., Jones, C.M., Ng, W.Y., Davey, G.M., Berthold, D., Holz, L., Kato, Y., Enders, M.H., Bayarsaikhan, G., Hendriks, S.H., Lansink, L.I.M., Engel, J.A., Soon, M.S.F., James, K.R., Cozijnsen, A., Mollard, V., Uboldi, A.D., Tonkin, C.J., de Koning-Ward, T.F., Gilson, P.R., Kaisho, T., Haque, A., Crabb, B.S., Carbone, F.R., McFadden, G.I. and Heath, W.R. (2017) Development of a Novel CD4(+) TCR Transgenic Line That Reveals a Dominant Role for CD8(+) Dendritic Cells and CD40 Signaling in the Generation of Helper and CTL Responses to Blood-Stage Malaria. The Journal of Immunology, 199, 4165-4179. https://doi.org/10.4049/jimmunol.1700186

[16] Bao, L.Q., Huy, N.T., Kikuchi, M., Yanagi, T., Senba, M., Shuaibu, M.N., Honma, K., Yui, K. and Hirayama, K. (2013) CD19(+) B cells Confer Protection against Experimental Cerebral Malaria in Semi-Immune Rodent Model. PLoS ONE, 8, e64836. https://doi.org/10.1371/journal.pone.0064836

[17] Moncunill, G., Mayor, A., Bardají, A., Puyol, L., Nhabomba, A., Barrios, D., Aguilar, R., Pinazo, M.J., Almirall, M., Soler, C., Muñoz, J., Gascón, J. and Dobaño, C. (2013) Cytokine Profiling in Immigrants with Clinical Malaria after Extended Periods of Interrupted Exposure to Plasmodium Falciparum. PLoS ONE, 8, e73360. https://doi.org/10.1371/journal.pone.0073360

[18] Yao, X., Wu, J., Lin, M., Sun, W., He, X., Gowda, C., Bolland, S., Long, C.A., Wang, R. and Su, X.Z. (2016) Increased CD40 Expression Enhances Early STING-Mediated Type I Interferon Response and Host Survival in a Rodent Malaria Model. PLoS Pathogens, 12, e1005930. https://doi.org/10.1371/journal.ppat.1005930

[19] Murray, S.A., Mohar, I., Miller, J.L., Brempelis, K.J., Vaughan, A.M., Kappe, S.H. and Crispe, I.N. (2015) CD40 is Required for Protective Immunity against Liver Stage Plasmodium Infection. The Journal of Immunology, 194, 2268-2279.

[20] Krause, R.G.E., Hurdayal, R., Choveaux, D., Przyborski, J.M., Coetzer, T.H.T. and Goldring, J.P.D. (2017) Plasmodium Glyceraldehyde-3-Phosphate Dehydrogenase: A Potential Malaria Diagnostic Target. Experimental Parasitology, 179, 7-19. https://doi.org/10.1016/j.exppara.2017.05.007

[21] Hill, C.P., Yee, J., Selsted, M.E. and Eisenberg, D. (1991) Crystal Structure of Defensin HNP-3, an Amphiphilic Dimer: Mechanisms of Membrane Permeabilization. Science, 251, 1481-1485. https://doi.org/10.1126/science.2006422

[22] Selsted, M.E., White, S.H. and Wimley, W.C. (1995) Structure, Function, and Membrane Integration of Defensins. Current Opinion in Structural Biology, 5, 521-527. https://doi.org/10.1016/0959-440X\%20(95)80038-7

[23] Zhao, L. and Lu, W. (2014) Defensins in Innate Immunity. Current Opinion in Hematology, 21, 37-42. https://doi.org/10.1097/MOH.0000000000000005

[24] Shunyi, Z. and Bin, G. (2013) Evolutionary Origin of $\beta$-Defensins. Developmental \& Comparative Immunology, 39, 79-84.

[25] Stotz, H.U., Thomson, J.G. and Wang, Y. (2009) Plant Defensins: Defense, Development and Application. Plant Signaling \& Behavior, 4, 1010-1012. https://doi.org/10.4161/psb.4.11.9755

[26] Chu, H., Pazgier, M., Jung, G., et al. (2012) Human $\alpha$-Defensin 6 Promotes Mucosal Innate Immunity through Self-Assembled Peptide Nanonets. Science, 337, 477-481. 
https://doi.org/10.1126/science.1218831

[27] Salvatore, M., García-Sastre, A., Ruchala, P., Lehrer, R.I., Chang, T. and Klotman, M.E. (2007) $\beta$-Defensin Inhibits Influenza Virus Replication by Cell-Mediated Mechanism(s). The Journal of Infectious Diseases, 196, 835-843.

https://doi.org/10.1086/521027

[28] Aldred, P.M.R., Hollox, E.J. and Armour, J.A.L. (2005) Copy Number Polymorphism and Expression Level Variation of the Human Alpha-Defensin Genes DEFA1 and DEFA3. Human Molecular Genetics, 14, 2045-2052. https://doi.org/10.1093/hmg/ddi209

[29] Khan, F.F., Carpenter, D., Mitchell, L., et al. (2013) Accurate Measurement of Gene Copy Number for Human Alpha-Defensin DEFA1A3. BMC Genomics, 14, 719. https://doi.org/10.1186/1471-2164-14-719

[30] Grishin, D.V. and Sokolov, N.N. (2014) Defensins-Natural Peptide Antibiotics of Higher Eukaryotes. Biomeditsinskaya Khimiya, 60, 438-447. https://doi.org/10.18097/pbmc20146004438

[31] Holly, M.K., Diaz, K. and Smith, J.G. (2017) Defensins in Viral Infection and Pathogenesis. Annual Review of Virology, 4, 369-391. https://doi.org/10.1146/annurev-virology-101416-041734

[32] Wilson, S.S., Wiens, M.E. and Smith, J.G. (2013) Antiviral Mechanisms of Human Defensins. Journal of Molecular Biology, 425, 4965-4980. https://doi.org/10.1016/j.jmb.2013.09.038

[33] Park, M.S., Kim, J.I., Lee, I., Park, S., Bae, J.Y. and Park, M.S. (2018) Towards the Application of Human Defensins as Antivirals. Biomolecules \& Therapeutics, 26, 242-254. https://doi.org/10.4062/biomolther.2017.172

[34] Ko, Y.H., Delannoy, M. and Pedersen, P.L. (1997) Cystic Fibrosis, Lung Infections, and a Human Trachealantimicrobial Peptide (hTAP). FEBS Letters, 405, 200-208. https://doi.org/10.1016/S0014-5793(97)00189-0

[35] Wilson, S.S., Wiens, M.E., Holly, M.K. and Smith, J.G. (2016) Defensins at the Mucosal Surface: Latest Insights into Defensin-Virus Interactions. Journal of Virology, 90, 5216-5218. https://doi.org/10.1128/JVI.00904-15

[36] Guerra, F.E., Borgogna, T.R., Patel, D.M., Sward, E.W. and Voyich, J.M. (2017) Epic Immune Battles of History: Neutrophils vs. Staphylococcus Aureus. Frontiers in Cellular and Infection Microbiology, 7, 286.

https://doi.org/10.3389/fcimb.2017.00286

[37] Abdossamadi, Z., Seyed, N., Zahedifard, F., Taheri, T., Taslimi, Y., Montakhab-Yeganeh, H., Badirzadeh, A., Vasei, M., Gharibzadeh, S. and Rafati, S. (2017) Human Neutrophil Peptide 1 as Immunotherapeutic Agent against Leishmania Infected BALB/c Mice. PLoS Neglected Tropical Diseases, 11, e0006123. https://doi.org/10.1371/journal.pntd.0006123

[38] Lafferty, M.K., Sun, L., Christensen-Quick, A., Lu, W. and Garzino-Demo, A. (2017) Human Beta Defensin 2 Selectively Inhibits HIV-1 in Highly Permissive CCR6 $^{+}$CD $^{+}$T Cells. Viruses, 9, 111. https://doi.org/10.3390/v9050111 